\title{
Egr-1 inhibits apoptosis during the UV response: correlation of cell survival with Egr-1 phosphorylation
}

\author{
Ruo-Pan Huang ${ }^{2}$, Yan Fan ${ }^{2}$, lan deBelle ${ }^{1}$, Zhengyu $\mathrm{Ni}^{1}$, \\ Wynette Matheny ${ }^{1}$ and Eileen D. Adamson ${ }^{1,3}$ \\ 1 The Burnham Institute 10901, N. Torrey Pines Rd, La Jolla, California 92037, \\ USA \\ 2 Molecular Medicine, Northwest Hospital, 120 Northgate Plaza, Suite 230, \\ Seattle, Washington 98125, USA \\ ${ }^{3}$ corresponding author: tel: (619)455-6480; fax: (619)646-3195 \\ e-mail: eadamson@ljcrf.edu
}

Received 10.6.97; revised 4.8.97; accepted 12.8.97

Edited by G. Melino

\begin{abstract}
UV irradiation of normal or immortalized cells induces a rapid increase in the expression of several transcription factors and is thought to serve a protective function. The human fibrosarcoma cell line, HT1080 clone H4, expresses almost undetectable levels of Egr-1 and does not respond to UV-C irradiation by the induction of Egr-1. The $\mathrm{H} 4$ cells are hypersensitive to UV which induces apoptosis and reduces clonogenicity. The introduction of exogenous Egr-1 into H4 (H4E9 and H4E4 cell-lines) confers protection from UV damage as measured by a number of assays. In both NIH3T3 (with inducible Egr-1) and H4E9 (constitutive Egr-1) cells, UV irradiation gave enhanced transactivation of Egr-1 reporters that correlated with phosphorylated Egr-1. Studies using inhibitors indicated that protein kinase-C and tyrosine kinases are involved in the anti-apoptotic effects of Egr-1 after UV damage. This is the first description of a biological effect of phosphorylated Egr-1.
\end{abstract}

Keywords: early growth response- 1 transcription factor; UV-C response; clonogenicity; phosphorylation; HT1080 fibrosarcoma cells; Egr-1 response element; transactivation

Abbreviations: CAT, chloramphenicol acetyl transferase; Egr-1, early growth response gene-1; UV-C, ultraviolet of wavelength $200-290 \mathrm{~nm}$

\section{Introduction}

Exposure to ultraviolet irradiation (UV) in mammalian cells triggers the UV response which is characterized by the induction of many genes (Fornace, 1992; Sachsenmaier et al, 1994a) including transcription factors such as Egr-1, AP-1 and $\mathrm{NF}-\kappa \mathrm{B}$. Activation of these transcription factors by UV is mediated through oxidative stress and/or DNA damage and cRas is a component in the signal transduction pathway (Engelberg et al, 1994; Devary et al, 1991, 1993). We have shown earlier that stimulation of activated Ras expression leads also to increased Egr-1 expression (Huang et al, 1994b). In addition, the UV signal generates reactive oxygen intermediates near the membrane and these activate a number of growth factor receptor kinases such as the Epidermal Growth Factor Receptor (EGFR) (Huang et al, 1996) upstream of Ras. Others have shown that UV irradiation enhances AP-1 activity and induces the nuclear translocation of NF- $\kappa \mathrm{B}$ (Radler-Pohl et al, 1993; Stein et al, 1989; Devary et al, 1992, 1993). Increased AP-1 activity has been shown to be implemented by the phosphorylation of the amino-terminal transactivation domain of c-Jun by the JNK ser/thr kinase (Hibi et al, 1993; Sluss et al, 1994; reviewed by Boulikas, 1995; Karin, 1994; Papavassiliou, 1994).

The irradiation of living organisms by ionizing or nonionizing electromagnetic waves can inflict damaging changes in replication fidelity if genes become mutagenized. Therefore, most living beings have devised ways of limiting such damage. In bacteria, UV activates the SOS response which is characterized by a number of phenotypic changes including enhanced capacity for DNA repair as well as mutagenesis, inhibition of cell division and prophage induction (Holbrook and Fornace, 1991). In mammalian cells, the UV response has been demonstrated to suppress the immune response (Kripke, 1994) in addition to serving a protective function against UV damage (Devary et al, 1992; Engelberg et al, 1994; Holbrook and Fornace, 1991; Lu and Lane, 1993). However, precise mechanisms for any protective function are unknown, although cell cycle arrest (Wang and Ellem, 1994; Orren et al, 1995; DiLeonardo et al, 1994; El-Deiry et al, 1994), DNA repair (Petersen et al, 1995) and the apoptotic process (Caelles et al, 1994; Lowe et al, 1993) are receiving a great deal of attention. By the elimination of cells with damaged genes by apoptosis or programmed cell death, the population is normalized. This long-term protective effect is necessary to eliminate the mutagenized cell that by chance may have become growth deregulated. Tumor cells have escaped the normal rules of cell regulation in a variety of ways, and survive as a population when normal counterparts would not. In many cases p53 is known to be mutant as in $\mathrm{H} 4$ cells but the most striking characteristic of this human tumor cell line is the almost complete absence of Egr-1 expression. The data fit the hypothesis that the lack of Egr-1 is a major influence in the transformed character of this and other human tumor cell lines. We have shown previously that $\mathrm{H} 4$, a clone of HT1080 cells (Anderson et al, 1994), stably expressing exogenous Egr-1 become growth inhibited, less transformed in vitro and less tumorigenic in a dose dependent fashion (Huang et al, 1995). In this case, Egr-1 has a tumor suppressor activity and protects cells by slowing the cell cycle so that DNA repair can occur.

The present analysis concerns the damage or other responses that UV irradiation inflicts on cells in vitro. and 
whether Egr-1 plays any role in these processes. The $\mathrm{H} 4$ line is ideal since it is incapable of eliciting Egr-1 expression after UV irradiation, unlike all other normal or immortalized cell lines tested. Using $\mathrm{H} 4$ cells and subclones that express high levels of exogenous Egr-1, we find that Egr-1 plays a different kind of role in cell protection after UV exposure. Egr-1 abrogates the apoptotic pathway so that more cells survive. To balance this effect, Egr-1 alters the cell cycle by becoming arrested in $S$ and G2 phases. We present evidence that UV stimulates substantial phosphorylation of Egr-1 after irradiation of H4E9 cells as well as normal immortalized cells (NIH3T3). This modification considerably enhances Egr-1 transactivation activity in H4E9 and NIH3T3 cells. We hypothesized that phosphorylated Egr-1 is more effective than nonphosphorylated Egr-1 in the abrogation of apoptosis. In support of this, the use of inhibitors of protein kinase $C$ (PKC) and tyrosine kinases that can inhibit the pathway leading to the phosphorylation of Egr-1, also reduce its transactivating activity as well as the anti-apoptotic role of Egr-1.

\section{Results}

\section{Egr-1 enhances cell survival after UV irradiation}

We demonstrated previously that reducing the endogenous Egr-1 levels in NIH3T3 cells using an antisense RNA expression vector, reduces cell survival in short term culture after UV irradiation (Huang and Adamson, 1995). To further extend this study, we turned the tumor cell line, HT1080 clone H4, which exhibits almost undetectable Egr1 even after stimulation by serum, UV and TPA as shown in Figure 1 (lanes 1 to 5). Such a cell line represents an ideal system to analyze the function of Egr-1 by introducing an expression vector that expresses exogenous Egr-1 stably and to different levels in individual clones (Huang et al, 1995). $\mathrm{H} 4 \mathrm{~N}$ is a G418-selected control line transfected with the empty vector pFCS; H4E4 and H4E9 are two clones expressing high levels of exogenous Egr-1. Other clones expressing lower levels of Egr-1 had reduced ability

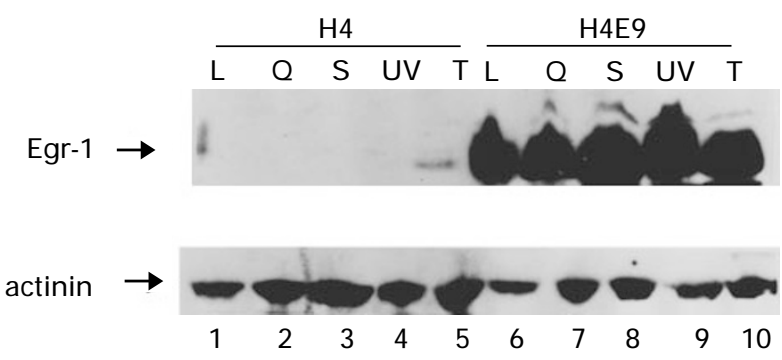

Figure 1 Immunoblot analysis of Egr-1 protein in human fibrosarcoma cell clones. $\mathrm{H} 4$ is a subclone that is highly tumorigenic and expresses little detectable Egr-1, lanes 1-5, even after stimulation with serum (S), ultraviolet $C$ irradiation (UV) or with tumor promoter TPA (T). $L=\log$ phase and $\mathrm{Q}=$ quiescent cells. $\mathrm{H} 4$ cells were transfected with an $\mathrm{Egr}-1$ expression vector and a clone that constitutively expresses Egr-1 was selected, H4E9. Expression of Egr-1 in H4E9 cells is also uninducible. To indicate approximately equivalent loading of the lanes, the blot was reprobed for the cytoskeleton protein, $\alpha$-actinin to slow growth. The constitutive high level of expression of Egr-1 in H4E9 is shown in Figure 1 (lanes 6-10) and is not further inducible by serum or UV. The morphology and growth characteristics of the cells over-expressing Egr-1 are altered; the cells are larger and flatter, better growth regulated, less transformed (anchorage-independent and clonogenic assays) and are less tumorigenic (Huang et al, 1995). We asked whether constitutively expressed Egr-1 could also confer protection against UV-induced growth inhibition in this cell model.

To test short term effects, cell lines expressing no Egr-1 $(\mathrm{H} 4$ and $\mathrm{H} 4 \mathrm{~N})$ and high levels of Egr-1 (H4E4 and H4E9) were treated with a (non-lethal) UV-C dose of $20 \mathrm{~J} / \mathrm{m}^{2}$. Following UV exposure, cell growth rates were determined by counting the number of cells up to 3 days later. As shown in Figure 2A, UV treatment significantly reduced the relative number of cells of parental $(\mathrm{H} 4)$ and control cells H4N) compared with high Egr-1 expressing clones. The Egr-1-expressing cell lines survived doses of up to $20 \mathrm{~J} / \mathrm{m}^{2}$ with only $5-8 \%$ reduction in relative cell numbers compared to $34 \%$ reduction in the controls after 2 days. The difference was greatest at a UV dose of $20 \mathrm{~J} / \mathrm{m}^{2}$;

A
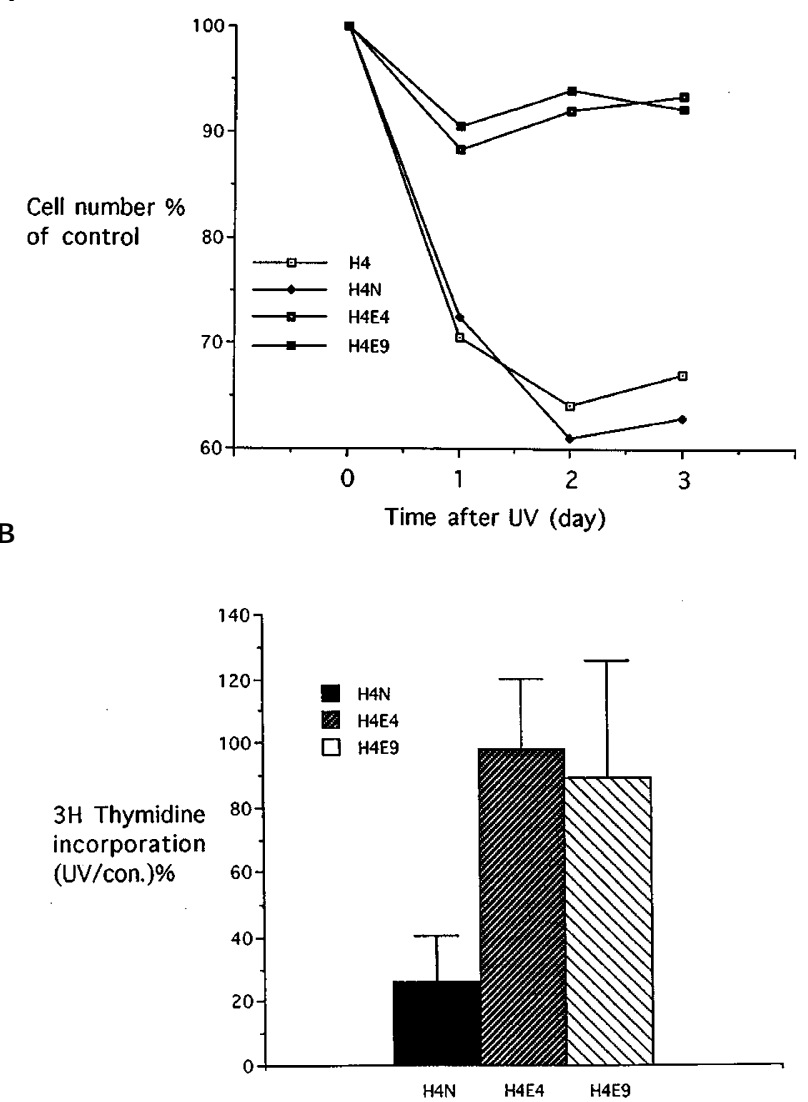

Figure 2 Cell growth after UV irradiation. (A) cell numbers were counted 1-3 days after $20 \mathrm{~J} / \mathrm{m}^{2}$ UV-C irradiation and expressed as a percentage of the nonirradiated cells. H4, parental cells; H4N G418-resistant control cells; H4E4 and H4E9 are two clones expressing high levels of exogenous Egr-1. (B) tritiated thymidine incorporation 2 days after irradiation $\left(20 \mathrm{~J} / \mathrm{m}^{2}\right)$ indicated that Egr-1containing clones synthesized DNA at normal levels while $\mathrm{H} 4 \mathrm{~N}$ control cells were damaged and recovered only $20 \%$ activity 
higher doses were lethal to all cell types (data not shown). The results were further confirmed by $\left[{ }^{3} \mathrm{H}\right]$ thymidine incorporation assays (Figure $2 \mathrm{~B}$ ). Here, the protective effect of Egr-1 2 days after irradiation was more obvious with $70-75 \%$ higher rates of DNA synthesis in Egr-1containing clones, H4E9 and H4E4 compared to the control line, $\mathrm{H} 4 \mathrm{~N}$.

To test long term effects of Egr-1 after UV irradiation, we performed clonogenic assays in plastic dishes. A known number of cells were plated and then exposed to increasing doses of UV-C from 0 to $40 \mathrm{~J} / \mathrm{m}^{2}$. After 3 weeks in culture, the numbers of colonies formed were determined and compared with the number of colonies in unirradiated cells (Figure 3). The clones expressing Egr-1 had a greater fractional survival compared to parental and control clones. The results suggest that exogenous Egr-1 has a long-term protective function against UV irradiation and one mechanism could be on the rate of cell death.

\section{Egr-1 protects cells from apoptosis after UV irradiation}

The clonogenic assay suggested that Egr-1 protected H4E9 cells against apoptosis induced by UV irradiation, three different methods were applied to test this hypothesis. First, cells with or without UV irradiation were treated with Hoechst dye to stain DNA and nuclei in cells. Epifluorescent microscopic observation was used to detect cells with morphological changes including nucleoplasmic condensation, nuclear fragmentation and formation of apoptotic bodies.

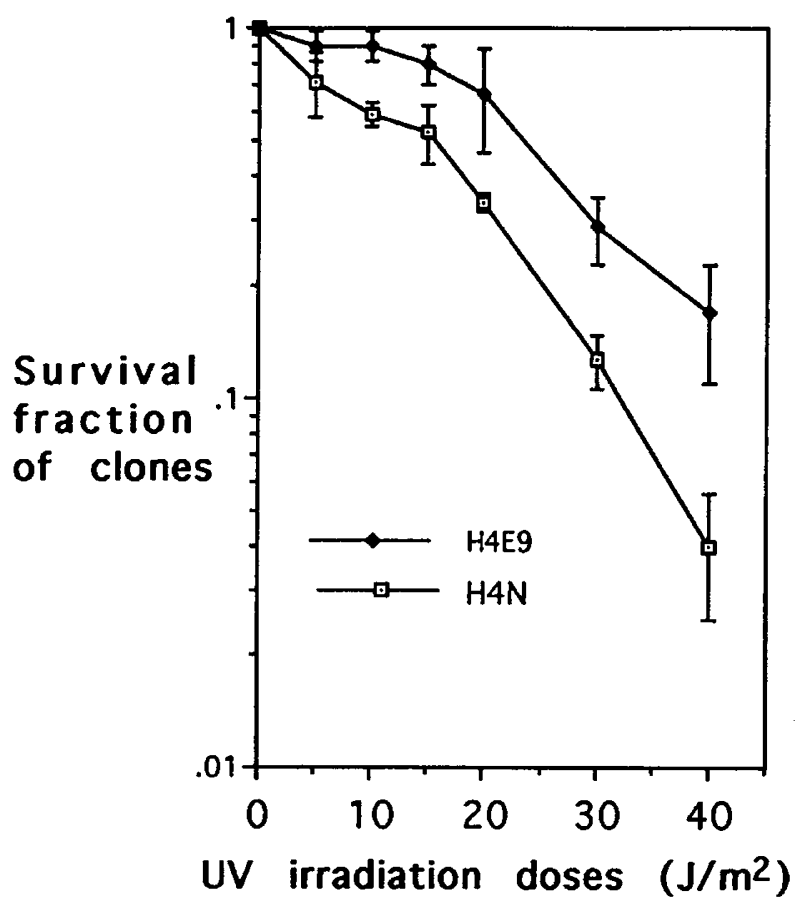

Figure 3 Survival fraction of clones following a range of doses of UV-C. Egr1 was protective in the clonogenic growth subsequent to irradiation expressed as a fraction of non-irradiated cells 14 days after irradiation. Surviving clones were counted and are expressed on a logarithmic scale against UV dose
As shown in Figure 4A, high Egr-1-expressing clones display less apoptosis after UV irradiation (Figure 4A, right panel). The numbers of apoptotic bodies were counted and compared in Figure 4B. There were fewer apoptotic cells in Egr-1-expressing cells $(7 \%)$ compared to control cells $(17 \%$, $P<0.01)$.

The second type of assay is more sensitive to DNA damage and adaptable to quantification. Cells were labeled with $\left[{ }^{3} \mathrm{H}\right]$ thymidine extensively before exposure to UV (the same $20 \mathrm{~J} / \mathrm{m}^{2}$ dose was used except where indicated). The radioactivity released from the cells was determined $24 \mathrm{~h}$ after exposure to UV. The results were normalized to untreated cells (Figure 5A). Again the same relationship between high levels of Egr-1 and lower apoptosis (59\% of control cells) was observed. In the third assay, genomic DNA was extracted from UV treated and untreated cells and separated on $2 \%$ agarose gels. As shown in Figure 5B (right panel), UV-treated $\mathrm{H} 4 \mathrm{~N}$ cells exhibited increased levels of fragmented and low mol. wt. DNA, in a dosedependent manner, visible as a DNA ladder and as a smear. Low mol. wt. DNA was detectable in all UV-treated cells but no laddering occurred in H4E9 cells (Figure 5B, left panel) whereas it was readily visible in $\mathrm{H} 4$ cells under the same conditions. Taken together, these data suggest that the process of programmed cell death is activated upon exposure of cells to UV irradiation and that Egr-1 inhibits the apoptotic pathway.

\section{Egr-1 functions by increasing the fraction of cells in S and G2 phases of the cell cycle after UV}

Cells were analyzed by fluorescence activated cell sorting (FACS) for the fraction of cells that remained in the G1 or G2 phases of the cell cycle that would account for the slower

A

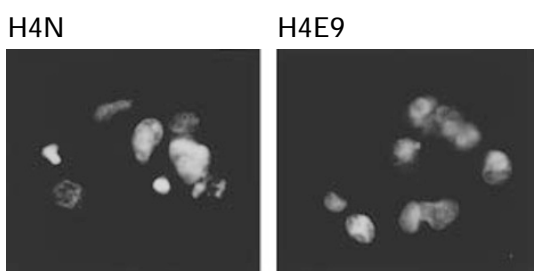

B

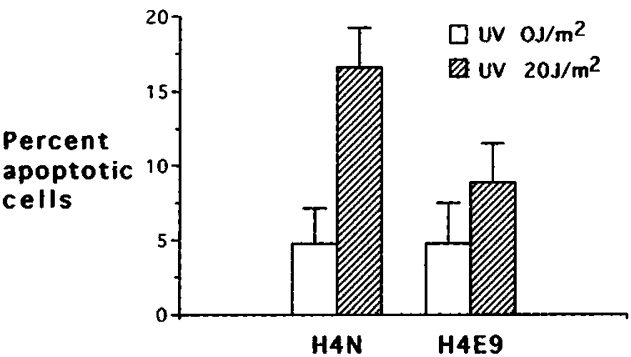

Figure 4 Apoptosis observed by Hoechst staining (A) of nuclei following irradiation. (B) the abnormal nuclei were counted and are expressed as $\%$ of cells counted in cultures of control H4N and H4E9 cells 
growth rates of the Egr-1-expressing cells. In unirradiated cells there was little difference between the two cell lines in the percentage of cells in each phase of the cell cycle (Figure 6 , table), although the cell cycle progressed more slowly in H4E9 cells. In these analyses, $24 \mathrm{~h}$ after a UV dose of $40 \mathrm{~J} / \mathrm{m}^{2}$, an apoptotic peak that denotes fragmented DNA, was prominent in $\mathrm{H} 4$ cells $(30 \%)$ and the $\mathrm{G} 1$ phase was depleted as cells underwent apoptosis. Irradiated H4E9 cells showed a more persistent $\mathrm{S}+\mathrm{G} 2 / \mathrm{M}$ phase compared to $\mathrm{H} 4 \mathrm{~N}$ and $\mathrm{H} 4$ cells and less apoptosis, in 3 experiments (a representative experiment is shown). The results suggest that the presence of Egr-1 protein expression in H4E9 cells leads to increased entry into $S$ and $G 2$ pausing, perhaps preventing apoptosis in

A

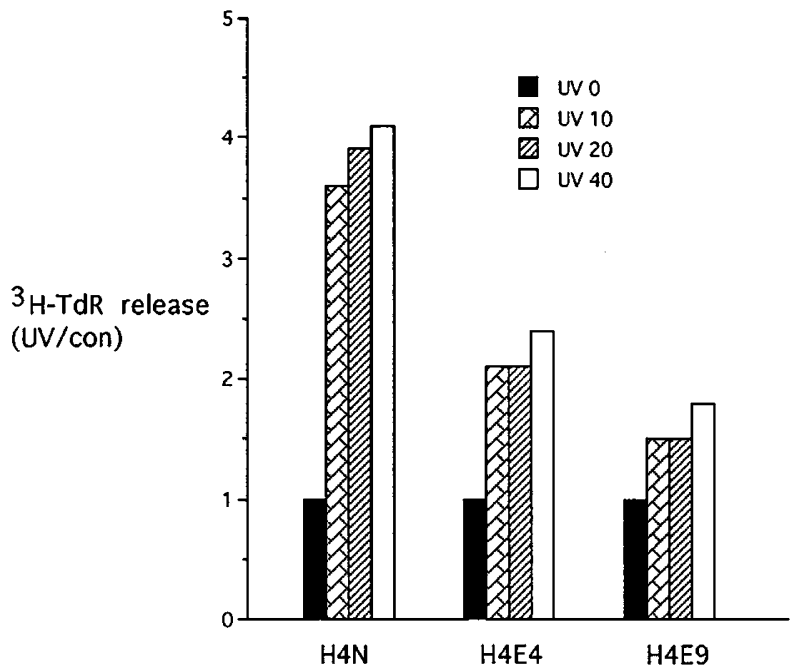

B

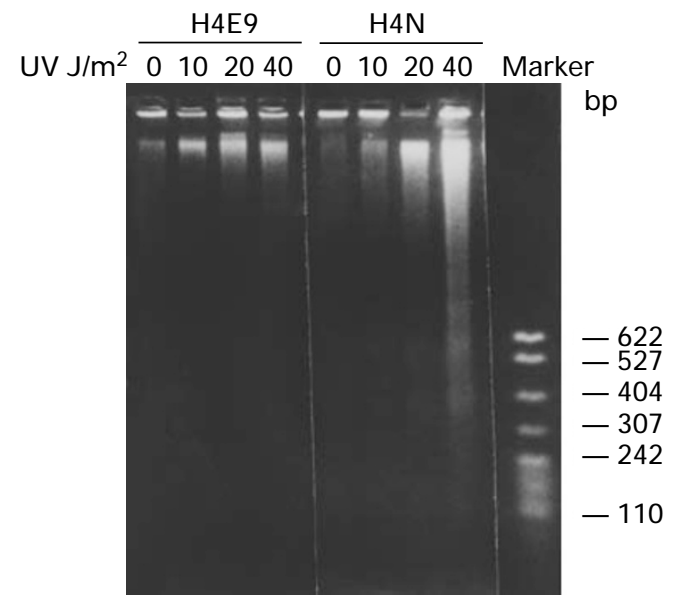

Figure 5 Apoptosis assays. (A) release of tritiated thymidine after UV irradiation. Cell DNA was extensively labeled by metabolic incorporation of tritiated thymidine before exposure to a range of doses of UV. DNA damage was dose-dependent, but was less in cells containing high levels of Egr-1, H4E4 and H4E9. (B) low Mol. Wt. DNA was extracted from cells after UV irradiation and analyzed on $2 \%$ agarose gels to show the pattern of breakdown products stained with ethidium bromide. $\mathrm{H} 4 \mathrm{~N}$ cells display detectable low Mol. Wt. DNA after UV irradiation while H4E9 cells were protected by the presence of Egr-1 this manner. The increased proportion of cells in S-phase is continued for at least 2 days as indicated by the data in Figure 2B.

\section{Egr-1 is phosphorylated in response to UV irradiation}

Our previous data showed that UV-C rapidly induces Egr-1 expression in NIH3T3 cells (Huang and Adamson, 1995). The increase in accumulated Egr-1 protein starts less than 10 min after irradiation and is maximal at $1-2 \mathrm{~h}$ before declining to base-line levels. The induction is at least partially transcriptional (data not shown) and, in addition, the protein is noticeably modified since it migrates at slower rates. In contrast, although serum and tumor promoters also induce Egr-1, very little of the slower migrating forms are seen. These slower migrating species are probably related to post-translational modifications such as phosphorylation, glycosylation or oxidation. To test whether phosphorylation of Egr-1 occurs, we examined
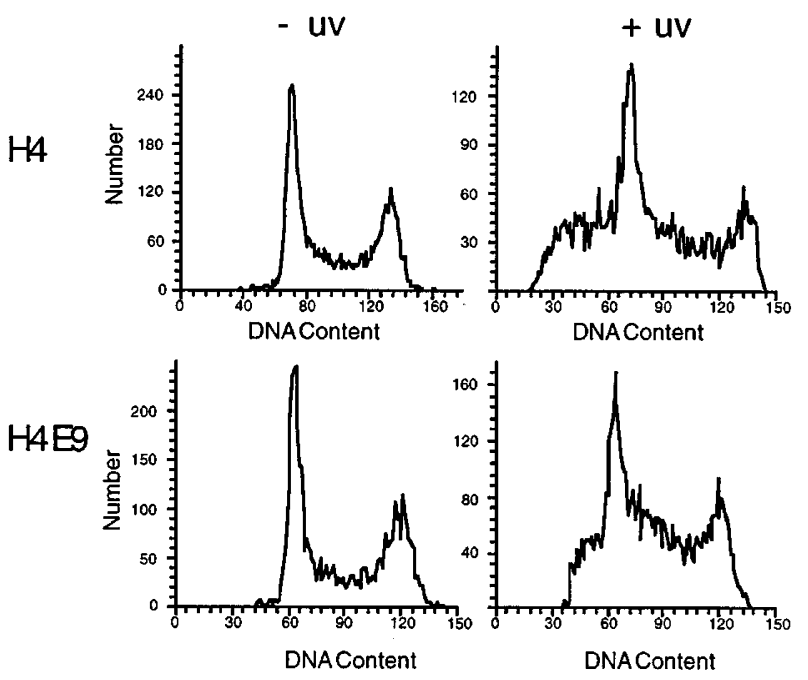

$\mathrm{H}$

H4E9

\begin{tabular}{|c|r|r|r|r|}
\hline uv & \multicolumn{1}{|c|}{+} & + & \multicolumn{2}{|c|}{+} \\
\hline GI & 41 & 25 & 40 & 26 \\
S & 29 & 28 & 30 & 38 \\
G2/M & 30 & 16 & 30 & 23 \\
Apop. & 0 & 30 & 0 & 13 \\
\hline
\end{tabular}

Figure 6 Cell Cycle Analysis. Cell cycles were analyzed in log phase growth (left panels) and $24 \mathrm{~h}$ following exposure of $\mathrm{H} 4$ (upper panels) and H4E9 (lower panels) cells of $40 \mathrm{~J} / \mathrm{m}^{2} \mathrm{UV}-\mathrm{C}$ (right panels). One of three similar cell cycle analyses is shown. The left-most shoulder in the irradiated samples represents apoptotic cells with subdiploid DNA content. The highest peak contains cells with a GO-G1 DNA content; whereas the right-most peak represents cells with G2/M DNA content. The region between the two peaks represents cells progressing through S-phase. The table shows the percentage of cells in each phase of the cell cycle 
the effects of UV on NIH3T3 cells incubated in the presence of $\left[{ }^{32} \mathrm{P}\right]$ orthophosphate for $2 \mathrm{~h}$ immediately after exposure to UV-C. As shown in Figure 7A, there was a large increase in immunoprecipitable phosphorylated Egr-1 that migrated at retarded electrophoretic mobility. This decrease in mobility was also observed in immunoprecipitates when cells were incubated with $\left[{ }^{35}\right.$ S]methionine (data not shown) or when immunoblotting was performed (Huang and Adamson, 1995). Slow-migrating forms of Egr-1 can be detected as long as $12 \mathrm{~h}$ after UV irradiation (data not shown). Our previous measurements of the induction of
Egr-1 in NIH3T3 cells by serum or by TPA gave 7 -tenfold increase in Egr-1 protein while the levels of slow-migrating phosphorylated Egr-1 were not increased by serum and only slightly increased by TPA (Huang et al, 1994b; Huang and Adamson, 1995). The results here suggest that UV significantly enhances both the Egr-1 protein level and its phosphorylation in NIH3T3 cells.

Since exogenous Egr-1 expression in H4E9 cells is invariant (Figure 1), we wished to determine if this preformed Egr-1 is also modified by UV irradiation of H4E9 cells. Figure 7B (upper left and right panels) shows

A

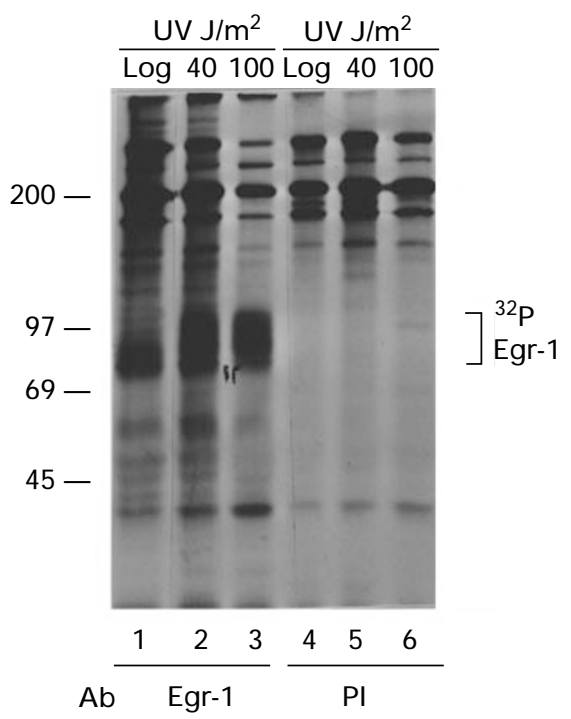

B

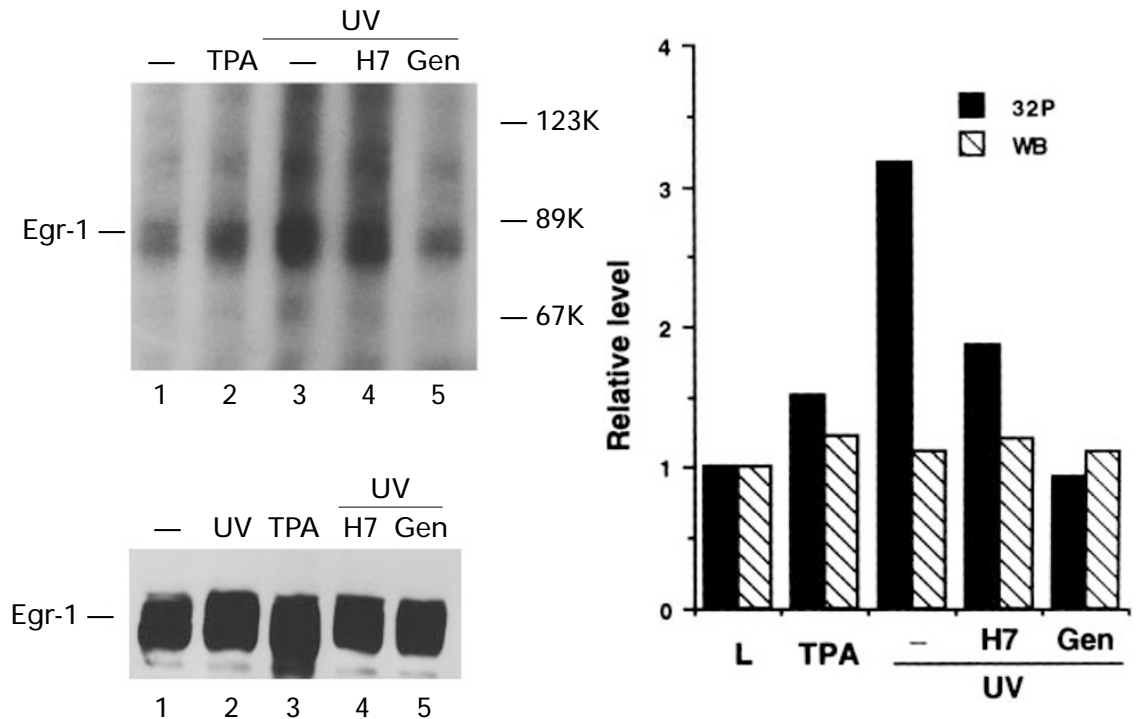

Figure 7 Immunoprecipitation analysis of phosphorylated Egr-1. (A) NIH3T3 cells were metabolically labeled with [32 Pi] immediately following exposure to two different doses of UV irradiation. After $2 \mathrm{~h}$, the cells were harvested and lysates were analyzed for the presence of radiolabeled Egr-1 using either the preimmune serum (lanes 4-6), or anti-Egr-1, (lanes 1-3). Cells in logarithmic growth produced phosphorylated Egr-1 and this was induced 4- to 5-fold after UV irradiation. (B) H4E9 cells were pretreated with $\mathrm{H} 7(30 \mu \mathrm{M})$ and Genistein $(100 \mu \mathrm{M})$ for $30 \mathrm{~min}$ in lanes 4 and 5 and metabolically labeled with $\left[{ }^{32}\right.$ Pi] immediately following exposure to UV or addition of TPA $(25 \mu \mathrm{M})$ for $2 \mathrm{~h}$, followed by immunoprecipitation with antibodies to Egr-1. Quantification (right) by radioactivity counting showed that UV enhanced phosphorylation more than three times compared to unstimulated cells. The phosphorylation was partially inhibited by PKC inhibitor, $\mathrm{H} 7$, and tyrosine kinase inhibitor, genistein $(G)$. Immunoblotting (bottom left) showed that steady state levels of Egr-1 did not change during these treatments 
that the small amount of phosphorylated Egr-1 in log phase cells was increased 1.5 -fold by the addition of TPA to the medium for $1 \mathrm{~h}$ and $>$ threefold by UV irradiation. The level of phosphorylation was somewhat reduced by co-incubation with $\mathrm{H} 7$ (a PKC inhibitor) and almost completely inhibited by the addition of genistein (a tyrosine kinase inhibitor). Hence, PKC and tyrosine kinases appear to be involved in the phosphorylation of constitutively expressed Egr-1. Genistein could be inhibiting the RTKs such as EGFR that are involved with signal generation after UV (Huang et al, 1996). However, in H4E9 cells, the total Egr-1 protein level remained unchanged as observed in Western blotting (Figure 7B, bottom left), therefore the results together suggested that UV irradiation of cells leads to the extensive phosphorylation of pre-existing Egr-1.

\section{Phosphorylated Egr-1 activates transcription more efficiently than non-phosphorylated}

We have previously documented that the phosphorylated forms of Egr-1 bind to the DNA target sequence to a greater degree compared to under-phosphorylated forms (Huang and Adamson, 1994). Irradiation induced the hyper-phosphorylated forms of Egr-1 and indicated that phosphorylated forms may be more active. To examine the transactivating activity of phosphorylated Egr-1, we used NIH3T3 cells that had been stably transfected with a reporter plasmid containing two Egr-1 binding sites, 2xEgr-1BSCAT, or with empty vector CAT-2 (as a control) together with pSVneo. Cells resistant to G418 were isolated and compared for their ability to activate chloramphenicol acetyl transferase (CAT) activity under various conditions. If active Egr-1 is produced after irradiation with UV, serum or TPA, it should stimulate CAT activity through binding to the Egr-1 binding sites. As shown in Figure 8, UV significantly induced 2xEgr-1BSCAT2 activity (11-18-fold) compared with serum (S) (twofold) or TPA addition (up to 1.7fold) and this effect was dose and time-dependent (Figure 8A and C). UV irradiation $\left(40 \mathrm{~J} / \mathrm{m}^{2}\right)$ also induced empty vector CAT activity (Figure $8 \mathrm{~B}$ ) to a small extent (2.5-fold). The results were further confirmed by transient transfection CAT assays (data not shown). The increased CAT activity after UV was not due to the induction of higher total Egr-1 protein levels by UV because Egr-1 levels were equally inducible by serum or TPA, but these agents did not greatly increase the transactivating activity of Egr-1. Rather, the increased transactivating activity of Egr-1 after UV irradiation was correlated with the level of slower-migrating phosphorylated Egr-1.

To distinguish between Egr-1 induction and Egr-1 phosphorylation by post-translational mechanisms, we took advantage of H4E9 cells in which the constitutively high exogenous Egr-1 level is not further inducible by UV, serum or TPA. The plasmid EBS $1^{3}$ fosCAT vector containing three Egr-1 binding sites, or a control vector $\mathrm{p} \Delta 56 \mathrm{fos} C A T$, was transfected into H4E9 cells. After $16 \mathrm{~h}$, cells were treated with UV, serum or TPA and CAT activities were determined $24 \mathrm{~h}$ later. Figure 9A shows that UV remarkably enhanced the already high basal CAT activity of the reporter construct by increasing transactivating activity of the Egr-1 binding site 6.5-fold (control vector was not stimulated). Furthermore, preincubation of H4E9 cells with tyrphostin, lavendustin (tyrosine kinase inhibitors) or $\mathrm{H} 7$ (PKC inhibitor), inhibited the transactivating of Egr-1 by $40-$ $60 \%$ (Figure 9C, 4 left lanes) down to the basal activity of the empty CAT vector (Figure 9C, 4 right lanes). UV did not induce EBS $1^{3}$ fosCAT activity in control H4N cells (Figure 9B) where Egr-1 levels were extremely low or absent. Increased Egr-1 protein stability per se did not contribute to the enhanced CAT activity since the protein stability was almost the same for total Egr-1 produced after UV and serum stimulation (data not shown). We concluded that hyperphosphorylated Egr-1, such as that produced after UV irradiation, is a more powerful transactivator of its target genes compared to under-phosphorylated Egr-1.

\section{The function of Egr-1 is modulated by both PKC and tyrosine kinases}

We have shown earlier that both protein kinase-C (PKC) inhibitors as well as tyrosine kinase inhibitors attenuate UV-

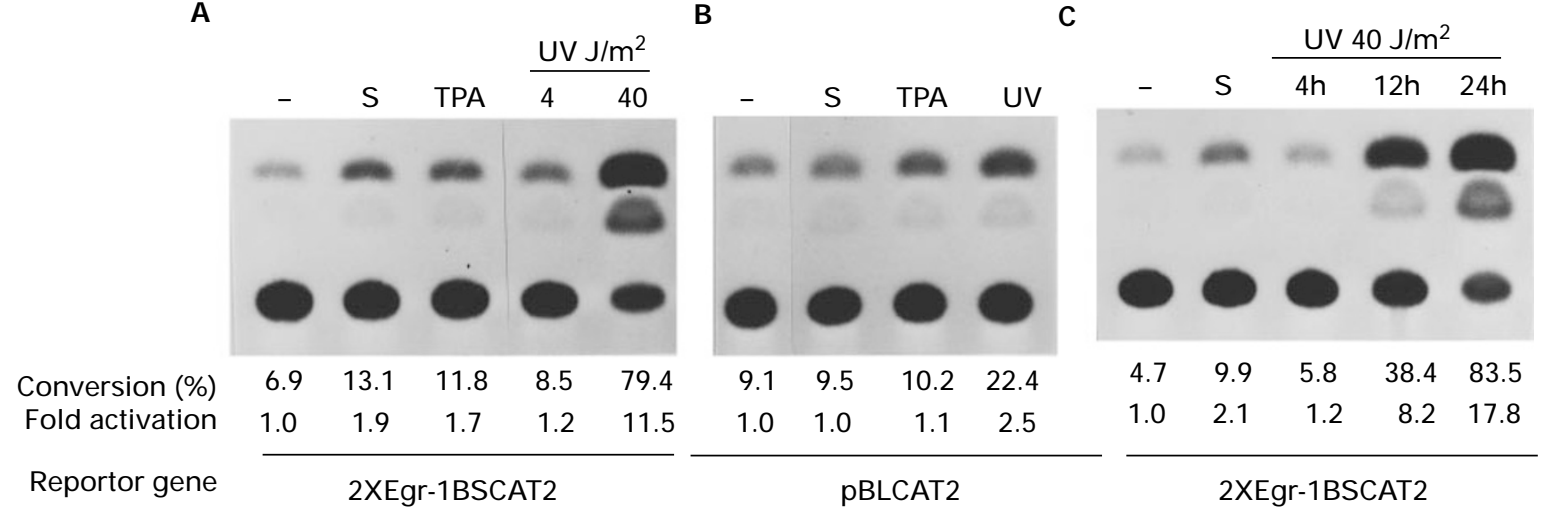

(1)

Figure 8 Phosphorylated Egr-1 activates its binding site with increased efficiency compared to non-phosphorylated Egr-1. NIH3T3 cells were transfected with reporter genes and selected for constitutive activity with G418. The 2xEgr-1 binding site, GCGGGGGCG, was ligated to the reporter BLCAT-2 construct to test for the transactivating activity of Egr- 1 measured $24 \mathrm{~h}$ later $(\mathbf{A})$ the addition of various stimuli to the cells: S, $20 \%$ serum; $0.2 \mu \mathrm{M}$ TPA; UV irradiation at 4 and $40 \mathrm{~J} / \mathrm{m}^{2}$. In (B) the cells expressed the empty vector, and $40 \mathrm{~J} / \mathrm{m}^{2}$ was used. In (C) the time course of activation was tested by harvesting cells at the times indicated for up to $24 \mathrm{~h}$. The values were expressed as fold-induction compared to the non-stimulated cells in log phase 

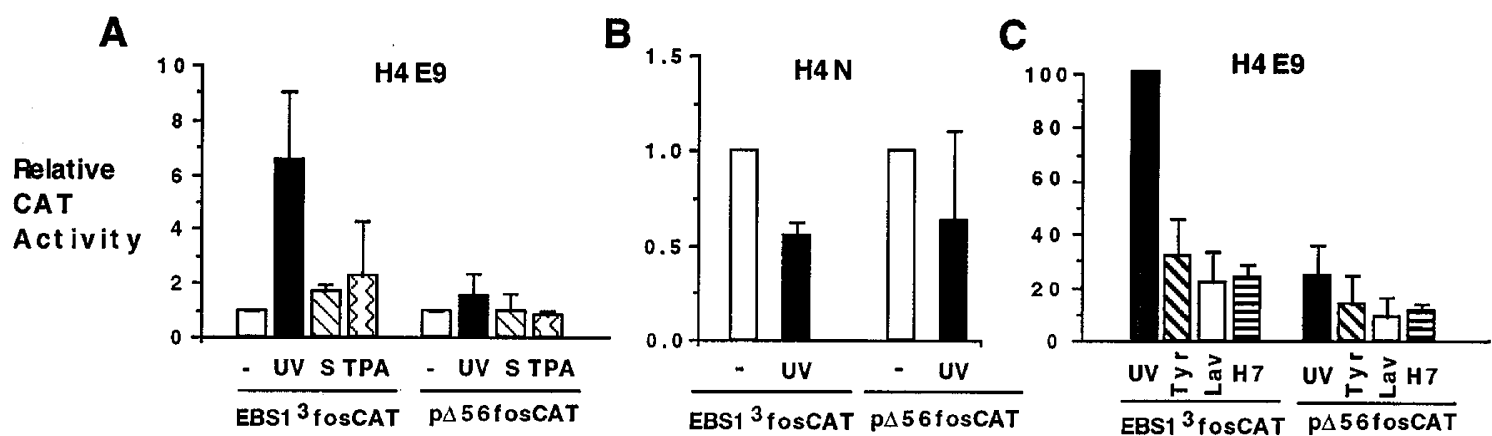

Figure 9 UV-induced enhanced Egr-1 transactivating activity in H4E9 cells. pEBS $1^{3}$ fosCAT reporter gene containing three Egr-1 binding sites, and control vector, $\mathrm{p} \Delta 56 \mathrm{fos} C \mathrm{CAT}$, were transiently transfected into $\mathrm{H} 4 \mathrm{E} 9$ or $\mathrm{H} 4 \mathrm{~N}$ control cells. The CAT activities were determined as indicated in the Methods section and quantified using the phosphorimager system. The experiment was repeated twice with the same results. (A) relative CAT activity after treatment of cells with UVC $\left(40 \mathrm{~J} / \mathrm{m}^{2}\right)$, serum $(20 \%)$ or TPA $(0.2 \mu \mathrm{M})(\mathrm{B}) \mathrm{H} 4 \mathrm{~N}$ cells were UV irradiated after transfection. (C) H4E9 cells were pretreated with kinase inhibitors 30 min before UV irradiation. $\mathrm{H} 7(30 \mu \mathrm{M}$, a PKC inhibitor), tyrphostin $(10 \mu \mathrm{M}$, a tyrosine kinase inhibitor) and lavendustin $\mathrm{A}(1 \mu \mathrm{M}$, a tyrosine kinase inhibitor)

induced phosphorylation of Egr-1 protein (Figure 7B, and Huang and Adamson, 1995). To test the role of phosphorylated Egr-1 in the protection of cells against UV damage, we used inhibitors of PKC and tyrosine kinases in growth assays in NIH3T3 cells. In these studies, $48 \mathrm{~h}$ pre-exposure to TPA was used to down-regulate PKC. Given a UV dose of $20 \mathrm{~J} / \mathrm{m}^{2}$, followed by a brief (30 min) exposure of the cells to the PKC inhibitor, $\mathrm{H} 7$, or to the tyrosine kinase inhibitors, genistein and tyrphostin, the ability of the cells to grow was subsequently tested in two ways. Figure 10A shows that all of these inhibitors significantly decreased the growth rate as measured by cell mass 2 days after UV irradiation. The long-term effects of these inhibitors on clonogenic growth of cells after irradiation (Figure 10B) was also measured. Kinase inhibitors reduced clonogenicity to $29-47 \%$ of irradiated cells that were not treated with inhibitors. The combination of protein kinase $\mathrm{C}$ inhibitor, $\mathrm{H} 7$, plus either tyrphostin or genistein was additive, reducing clonogenicity to $8 \%$ that of untreated, irradiated cells, suggesting that two Egr-1 phosphorylating signal pathways are operating independently during the cell's response to UV injury.

\section{Discussion}

A summary of the strategy used in these studies is presented in Figure 11. The data presented here suggest that UV irradiation induces substantial hyperphosphorylation of Egr-1 which subsequently enhances Egr-1 transactivation ability. It has been reported previously that Egr-1 is a nuclear phosphoprotein (Grover-Bardwick et al, 1994; Cao et al, 1990), however, the biological significance of this modification was unknown. Recently, we observed that the phosphorylated forms of Egr-1 bound to DNA more efficiently than nonphosphorylated (Huang and Adamson, 1994). We also found that Egr-1 as well as JunB, JunD and C-Jun were strongly phosphorylated in NIH3T3 cells conditionally over-expressing $\mathrm{v}$-sis oncogene (Huang et al, 1994a). Results from other groups showed that the application of the phosphatase inhibitor, okadaic acid, to mouse fibroblasts cells increased the transactivation of the Egr-1 gene and increased the phosphorylated forms of the protein (Cao et al, 1992). All of
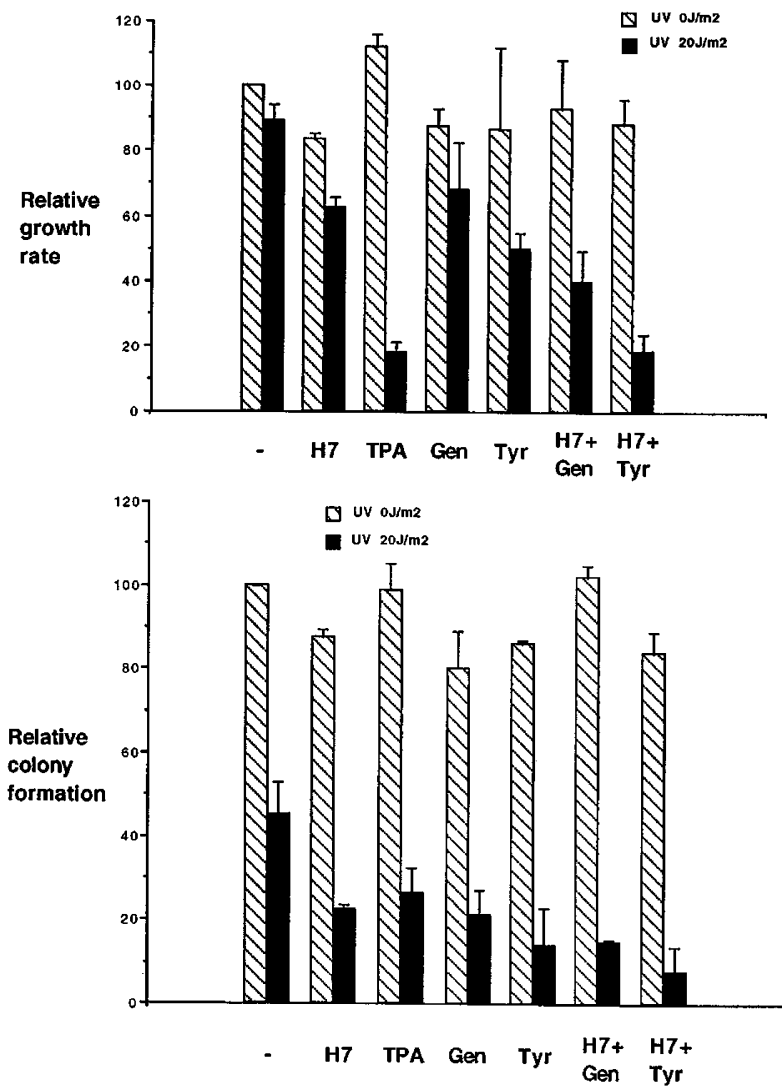

Figure 10 The effect of kinase inhibitors on cell growth rates after UV irradiation. Growth was measured 2 days after irradiation and compared with non-irradiated cells. Inhibitors were added $30 \mathrm{~min}$ before UV exposure (except for TPA which was added for $48 \mathrm{~h}$ earlier to down-regulate PKC activity) and growth was then measured. (A) cell mass after 2 days in 96-well plates (MTT assay, see the Methods Section). (B) clonogenic growth 2-3 weeks after seeding cells in plastic tissue culture dishes

these observations support the notion that phosphorylated modifications of Egr-1 (only Ser and Thr appear to be phosphorylated) may have profound importance to its biological functions. Our results suggest that these functions may be realized via increased transactivation ability. One of 
the target genes of Egr-1 in its growth inhibitory role is the TGF $\beta$ gene (Liu et al, 1996). Although we have not yet identified the relevant target genes for anti-apoptosis, several UV responsive genes (c-Ha-ras, c-abl, jun-B, c-fos, mouse metallothionein I, TNF $\alpha$ ) contain Egr-1 binding sites (Holbrook and Fornace, 1991) and phosphorylated Egr-1 may subsequently activate or inhibit such target genes (Krämer et al, 1994). The UV-induced phosphorylation of Egr-1 involves both the PKC and tyrosine kinase pathways because the inhibition of these kinase activities significantly reduced Egr-1 phosphorylation (Figure 7B), transactivating ability (Figures 8 and 9) and cell survival after UV (Figure 10).

In mammalian cells, UV exposure turns on the UV response process which is characterized by increased levels of transcription factors including Egr-1 and AP-1 and increased stabilization of p53 (Liu et al, 1994). The biological function of the mammalian UV response is just beginning to be understood. By using tyrosine kinase inhibitors, Devary et al (1991) showed that UV-elicited AP-1 response has protective functions. Here, we provide evidence, at the individual gene level, that Egr-1 functions in the protection of cells against UV damage that leads to decreased clonogenicity. There are at least two components that could contribute to the protective effect of Egr-1. One is that constitutive Egr-1 expression slows the cell cycle (especially in the G2 phase, data not shown) so that DNA repair enzymes have a greater ability to replace damaged DNA. In addition, after UV irradiation, the ratio of cells in the S and G2 phases of the cell cycle increase significantly in H4E9 cells but not in $\mathrm{H} 4 \mathrm{~N}$ control cells (Figure 4, Figure 6 Table). The second is that the stimulus to enter the apoptotic pathway in radiosensitive parental $\mathrm{H} 4$ cells, is avoided in Egr-1expressing $\mathrm{H} 4$ cells. As a result, the higher fraction of cells survive in Egr-1-containing cells compared to Egr-1-minus

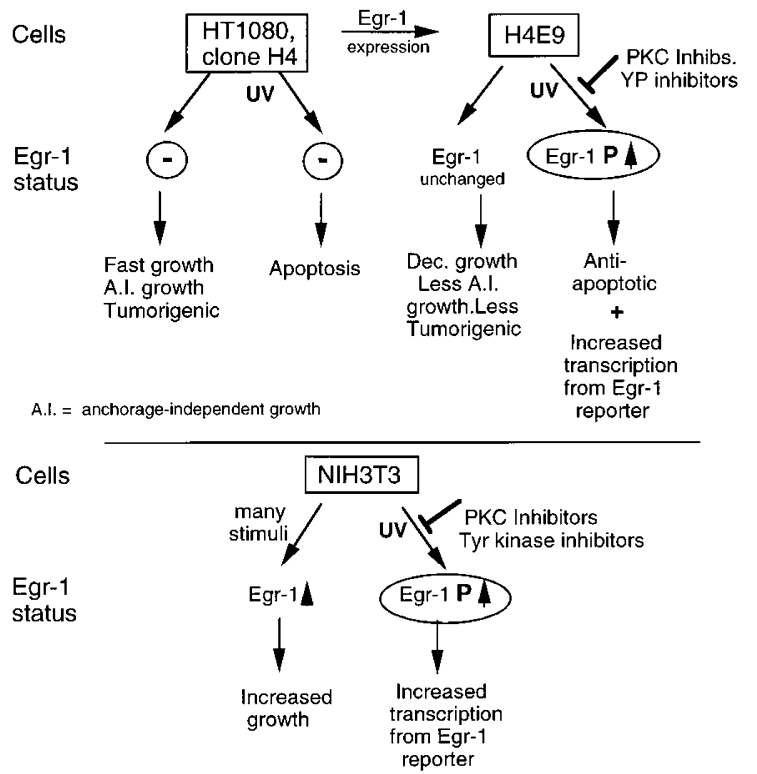

Figure 11 Summary of cell lines and strategy used to show that phosphorylated Egr-1 has elevated transactivating activity that correlates with anti-apoptotic activity parental $\mathrm{H} 4$ cells. Our conclusion is also supported from other studies in which pretreatment of the human astrocytoma cell line, G18, with taxol enhanced radiosensitivity. Careful examination of seven immediate early genes including Egr-1, c-jun and c-fos, revealed that only Egr-1 was significantly inducible by radiation in $\mathrm{G} 18$ cells and the induction was blocked by pretreatment of cells with taxol (Gubits et al, 1993). Interestingly, the UV response pathway involving Ras and AP-1 (and perhaps including Egr-1) is highly conserved between yeast and mammals (Engelberg et al, 1994), although the evolutionary significance of the UVinduced process is unclear. Perhaps the UV response in eukaryotic cells represents an 'SOS' type of response to UV, designed to restore the balance between UV damage and the normality of the cell population.

Previously, we have shown that both PKC and tyrosine kinase activities are necessary intermediates in cell survival after UV irradiation. The results here are consistent with the report of Devary et al (1992) that tyrosine kinase inhibitors greatly enhance the cytotoxic effect of UV-C in Hela cells. Evidence from Hallahan et al (1992) which showed that inhibition of protein kinase C potentiates cell killing by ionizing radiation also complements our observation. The role of tyrosine kinase in the UV signal transduction pathway has been well documented. Several tyrosine kinases, such as EGF-receptor (Sachsenmaier et al, 1994b; Huang et al, 1996) and vsrc, (Devary et al, 1992) have been identified in the UV signal cascade. The role of $\mathrm{PKC}$ is much more complicated. By employing broad specificity protein kinase inhibitors such as $\mathrm{H} 7$, other groups (Buscher et al, 1988; Hallahan et al, 1991; Papathanasiou et al, 1991) also observed that PKC is involved in the UV response. PKC has been demonstrated to activate the gene products of c-raf and c-mos proto-oncogenes which are serine/threonine protein kinases. Particularly c-mos has been shown to participate in PKC-mediated signal transduction pathways. However further experiments are needed to define the specific role of PKC in UV signaling.

Finally, the more challenging question we are facing comes from our recent finding that Egr-1 negatively regulates human tumor cell growth. Currently, we hypothesize that Egr-1 performs distinct functions dependent on its phosphorylation states and also serves several roles in cell cycle regulation. For example, cells carrying Egr-1 appear to arrest the cell cycle in S and G2 after UV irradiation, thereby allowing cells to repair any DNA damage. As a result, cells might be expected to increase in survival after UV irradiation. On the other hand, cells lacking Egr-1 will proceed to programmed cell death. Consequently, these cells might be expected to have increased sensitivity to UV irradiation. This idea is supported by our finding that Egr-1 can increase cell survival by inhibiting the apoptotic pathway, by arresting cell cycling and by allowing cell clonogenicity to proceed at higher levels than in the absence of Egr-1. The data support a model that phosphorylated Egr-1 is the form that is most able to protect cells after damage caused by UV irradiation. 


\section{Materials and Methods}

\section{Cell culture and materials}

$\mathrm{NIH} 3 \mathrm{~T} 3$ cells were grown in DME containing $5 \% \mathrm{CS}$ at $37^{\circ} \mathrm{C}$ and $5 \% \mathrm{CO}_{2}$ HT1080 derived clones H4 (Frisch and Francis, 1994), H4N, H4E4 and H4E9 (Huang et al, 1995) were maintained in DME supplemented with $10 \% \mathrm{FCS}$ at $37^{\circ} \mathrm{C}$ in $5 \% \mathrm{CO}_{2}$. UV irradiation was performed as described elsewhere (Huang and Adamson, 1995). H7 and TPA were obtained from Sigma Chem. Co. (St. Louis, MO). Tyrphostin, lavendustin and genistein were purchased from Gibco-BRL (Gaithersburg, MD). Stock solutions were prepared as below: genistein, $20 \mathrm{mM}$ in DMSO; lavendustin, $10 \mathrm{mM}$ in water; $\mathrm{H} 7,30 \mathrm{mM}$ in water; TPA, $0.25 \mathrm{mM}$ in DMSO and tyrphostin $10 \mathrm{mM}$ in DMSO. The working concentrations were $20 \mu \mathrm{M}, 1$ $2 \mu \mathrm{M}, 10 \mu \mathrm{M}, 0.2 \mu \mathrm{M}$ and $10 \mu \mathrm{M}$, respectively.

\section{Plasmid construction}

Plasmid 2xEgr-1BSCAT-2, containing two copies of the Egr-1 DNA binding site, was created by cloning of synthetic oligonucleotides containing $5^{\prime}$-GATCTCCTCGCCCCCGCGAGT into the BamHI site in pBLCAT-2. The correct orientation, copy number and identity of clones were confirmed by dideoxynucleotide sequencing. The reporter plasmid, p $\Delta 56$ fosCAT, containing the murine minimal fos reporter upstream of the chloramphenicol acetyl transferase gene, and $\mathrm{EBS} 1^{3}$ fosCAT with three copies of a high affinity Egr-1 binding site, have been described (Gashler et al, 1993).

\section{Transfection}

NIH3T3 cells $\left(1 \times 10^{6}\right)$ were seeded into $100 \mathrm{~mm}$ tissue culture dishes $20 \mathrm{~h}$ prior to transfection. $20 \mu \mathrm{g}$ of CAT vectors (pBLCAT-2 or 2xEgr1BSCAT) plus $2 \mu \mathrm{g}$ of pSVneo (for selection with G418) were cotransfected by calcium phosphate precipitation. After incubation overnight, the medium was replaced with fresh medium. Forty hours after transfection the cultures were trypsinized and seeded at a $1: 4$ ratio for selection with G418 at $400 \mu \mathrm{g} / \mathrm{ml}$. Three weeks later, all the clones so formed were pooled together for further experiments. For transient expression studies, cells were harvested $40-48 \mathrm{~h}$ after transfection.

\section{CAT assay}

The stably transfected cells were seeded at $2 \times 10^{5}$ cells on a $60 \mathrm{~mm}$ plate. Twenty four hours later, cells were treated with UV (20 $\left.\mathrm{J} / \mathrm{m}^{2}\right)$ or TPA $(0.2 \mu \mathrm{M})$. For serum stimulation, cells were incubated in DME containing $0.5 \% \mathrm{CS}$ for $24 \mathrm{~h}$ and then $20 \%$ serum was added. For all types of stimulation, cells were harvested $24 \mathrm{~h}$ after transfection, lysed and assayed for CAT activity as described earlier (Huang et al, 1994b).

\section{Immunoprecipitation}

Cells were metabolically labeled by incubation in phosphate-free DME containing Tris-buffered dialyzed serum and $0.5 \mu \mathrm{Ci}$ of $\left[{ }^{32} \mathrm{P}\right] \mathrm{inorganic}$ phosphate (ICN, Irvine, CA) immediately after UV irradiation or addition of TPA. Equal amounts of radioactivity were subjected to immunoprecipitation using a rabbit antibody to an Egr-1 fusion protein product as described earlier (Huang and Adamson, 1993).

\section{Western blotting}

Egr-1 protein in cell lysates was assayed by immunoblotting as described (Huang et al, 1994b). Equal loading of the lanes was verified by reprobing the washed membrane with an antibody to $\alpha$-actinin (Sigma Corpn., St Louis, MO).

\section{Growth assays following irradiation}

To test clonogenicity on plastic substrates, colony-forming assays were done by seeding 500 (NIH3T3 and H4N) or 1000 (H4E9) cells per $60 \mathrm{~mm}$ plate. The plates were irradiated with the indicated dose of UV$C$ provided by a Stratolinker 420 , and culture continued with feeding every 3 days. After 2 to 3 weeks, the plates were washed in PBS, fixed in $4 \%$ formaldehyde-PBS and stained with Giemsa solution. Colonies containing $>50$ cells were counted and analyzed statistically by the students two-tailed $t$ test.

Growth rates by cell counting assays. Five $\times 10^{4}$ cells $\mathrm{H} 4, \mathrm{H} 4 \mathrm{~N}$, H4E4 and H4E9 were seeded in each well of a 6-well plate. After $20-$ $24 \mathrm{~h}$, cells were treated with indicated amounts of UV-C and allowed to grow for varying times. The trypsinized cells were counted using a Coulter counter. Assays were performed in triplicate and repeated at least twice.

Non-radioactive cell proliferation assay (MTT, Promega, Madison, WI). The tetrazolium dye end product of MTT assays was measured in a 96-well plate. NIH3T3 cells were seeded in 6well plates at $5 \times 10^{4}$ per well and cultured overnight. Cells were irradiated with $20 \mathrm{~J} / \mathrm{m}^{2}$ after pretreatment with different inhibitors for 30 min (except that TPA treatment was continued for $48 \mathrm{~h}$. Cells were trypsinized, suspended in $1 \mathrm{ml}$ of medium containing inhibitors and transferred to 96 well plates $(100 \mu /$ well). After 2 days, cells were stained and processed as described by the manufacturer. The values of absorbances at $600 \mathrm{~nm}$ were plotted as a measure of the relative number of cells. Each assay was done in quadruplicate and repeated at least twice.

Tritiated thymidine incorporation. Five $\times 10^{4}$ cells were seeded in 6-well plates for culture overnight and then subjected to $20 \mathrm{~J} / \mathrm{m}^{2}$ UV-C irradiation. Two days later, the cells were treated with $1.0 \mu \mathrm{Ci} /$ well tritiated thymidine for $2 \mathrm{~h}$. The cells were washed, fixed in Carnoy's fixative (methanol:glacial acetic acid, 3:1), dissolved in $0.3 \mathrm{M} \mathrm{NaOH}$ and counted in a scintillation counter. To assay for apoptosis, cells were extensively labeled by culture with tritiated thymidine overnight, the cells were washed with PBS three times and then exposed to UV irradiation at the indicated dose. Culture was continued for $24 \mathrm{~h}$. The amount of tritium released into the supernatant was determined by counting aliquots in a scintillation counter.

\section{Cell cycle analyses}

Cells were harvested in logarithmic growth phase and seeded in $100 \mathrm{~mm}$ tissue culture plates at $5 \times 10^{5}$ to $10^{6} / \mathrm{dish}$. The next day, the medium was removed and cells were exposed to UV-C irradiation at various doses, the same medium was replaced and culture was continued for various times before harvesting. Cells were washed twice in PBS and detached in $\mathrm{Ca} / \mathrm{Mg}$-free PBS containing $1 \mathrm{mM}$ EDTA. The cells were triturated to disaggregate, centrifuged, resuspended and fixed in $70 \%$ ethanol. The DNA in cells was stained by exposure to propidium iodide and cells were analyzed in a fluorescence activated cell sorter (Model FACSort, Becton Dickinson).

\section{Apoptosis assays}

Cells were fixed in Carnoy's solution (methanol:glacial acid, 3:1) and stained with $5 \mu \mathrm{g} / \mathrm{ml}$ of bisbenzimide trihydrochloride (Hoechst 33258) for $20 \mathrm{~min}$. A Nikon Biophot microscope was used to observe nuclei 
and fragmented nuclei. Counts were made of at least 500 nuclei in each cell line. The experiment was repeated once and statistical analyses made.

DNA fragmentation: $1 \times 10^{6}$ of $\mathrm{H} 4 \mathrm{~N}$ and H4E9 cells were seeded on $100 \mathrm{~mm}$ plates and incubated overnight. Cells were exposed to UV$\mathrm{C}$ as indicated. After $24 \mathrm{~h}$, cells (detached and attached) were harvested. Cells were lysed in 0.5\% Triton X-100, $10 \mathrm{mM}$ EDTA and $10 \mathrm{mM}$ Tris $\mathrm{pH} 7.4$ and low molecular weight genomic DNA was extracted by phenol-chloroform three times as described (Frisch and Francis, 1994).

Tritiated thymidine release (see above in Growth assays).

\section{Acknowledgements}

We are grateful to $\mathrm{Dr}$ S. Frisch for the $\mathrm{H} 4$ cell line and for many helpful discussions. Dr V. Sukhatme generously provided the p $\Delta 56$ fos-CAT and EBS $^{3}$ fos-CAT for reporter studies. We thank Drs C. Hauser and D. Mercola, for critical reading of the manuscript. This work was supported by grants from the Public Health Service: HD 21957 and CA 28427 (EDA).

\section{References}

Anderson MJ, Casey G, Fasching CL and Stanbridge EJ (1994) Evidence that wildtype TP53, and not genes on either chromosome I or II, controls the tumorigenic phenotype of the human fibrosarcoma HT1080. Genes, Chromosomes Cancer 9: $266-281$

Boulikas T (1995) Phosphorylation of transcription factors and control of the cell cycle. Critical Reviews in Eukaryotic Gene Expression 5: 1-77

Buscher M, Rahmsdorf HJ, Litfin M, Karin M and Herrlich P (1988) Activation of the Cfoc gene by UV and phorbol ester: different signal transduction pathways converge to the same enhancer element. Oncogene 3: 301-311

Caelles C, Helmberg A and Karin M (1994) p53-Dependent apoptosis in the absence of transcriptional activation of p53-target genes. Nature 370: $220-$ 223

Cao X, Koshi RA, Gashler A, McKiernan M, Morris CF, Gaffney R, Hay RV and Sukhatme VP (1990) Identification and characterization of the Egr-1 gene product, a DNA-binding zinc finger protein induced by differentiation and growth signals. Mol. Cell Biol. 10: 1931-1939

Cao X, Mahendran R, Guy GR and Tan YH (1992) Protein phosphatase inhibitors induce the sustained expression of the Egr-1 gene and the hyperphosphorylation of its gene product. J. Biol. Chem. 267: 12991-12997

Devary Y, Gottlieb RA, Lau LF and Karin M (1991) Rapid and preferential activation of the $c$-jun gene during the mammalian UV response. Mol. Cell Biol. 11: $2804-$ 2811

Devary Y, Gottlieb RA, Smeal T and Karin M (1992) The mammalian ultraviolet response is triggered by activation of Src tyrosine kinases. Cell 71: 1081-1091

Devary Y, Rosette C, DiDonato JA and Karin M (1993) NF-kappa B activation by ultraviolet light not dependent on a nuclear signal. Science 261: 1442-1445

DiLeonardo A, Linke SP, Clarkin K and Wahl GM (1994) DNA damage triggers a prolonged p53-dependent $\mathrm{G} 1$ arrest and long-term induction of Cip1 in normal human fibroblasts. Genes Dev. 8: 2540-2551

El-Deiry WS, Harper JW, O'Connor PM, Velculescu VE, Canman C, Jackman J, Pietenpol JA and Burrell Mea (1994) WAF1/CIP1 is induced in p53-mediated G1 arrest and apoptosis. Cancer Research 54: 1169-1174

Engelberg D, Klein C, Martinetto H, Struhl K and Karin M (1994) The UV response involving the Ras signaling pathway and AP-1 transcription factors is conserved between yeast and mammals. Cell 77: $381-390$

Fornace AJJ (1992) Mammalian genes induced by radiation; activation of genes associated with growth control. Annu. Rev. Genet. 26: 507-526

Frisch SM and Francis H (1994) Disruption of epithelial cell matrix interactions induces apoptosis. J. Cell Biol. 124: 619-626

Gashler AL, Swaminathan S and Sukhatme VP (1993) A novel repression module, an extensive activation domain, and a bipartite nuclear localization signal defined in the immediate-early transcription factor EGR-1. Mol. Cell Biol. 13: 4556-4571
Grover-Bardwick A, Adamson ED and Mercola DA (1994) Transformation-specific pattern of phosphorylation of c-Jun, Jun-B, Jun-D, and Egr- 1 in v-sis transformed cells. Carcinogenesis 15: 1667-1674

Gubits RM, Geard CR and Schiff PB (1993) Expression of immediate early genes after treatment of human astrocytoma cells with radiation and taxol. Int. J. Radiat. Oncol. 27: 637-642

Hallahan DE, Sukhatme VP, Sherman ML, Virudachalam S, Kufe D and Weichselbaum RR (1991) Protein kinase C mediates X-ray inducibility of nuclear signal transducers EGR1 and JUN. Proc. Natl. Acad. Sci. USA 88: $2156-2160$

Hallahan DE, Virudachalam S, Schwartz JL, Panje N, Mustafi R and Weichselbaum RR (1992) Inhibition of protein kinases sensitizes human tumor cells to ionizing radiation. Radiat. Res. 129: $345-350$

Hibi M, Lin A, Smeal T, Minden A and Karin M (1993) Identification of an oncoproteinand UV-responsive protein kinase that binds and potentiates the c-Jun activation domain. Genes Dev. 7: 2135-2148

Holbrook NJ and Fornace AJJ (1991) Response to adversity: molecular control of gene activation following genotoxic stress. New Biol. 3: 825-833

Huang R-P and Adamson ED (1993) Characterization of the DNA-binding activity of the early growth response-1 (EGR-1) transcription factor: evidence for modulation by a redox mechanism. DNA and Cell Biology 12: 265-273

Huang R-P and Adamson ED (1994) The phosphorylated forms of the transcription factor, Egr-1, bind to DNA more efficiently than non-phosphorylated. Biochem. Biophys. Res. Commun. 200: 1271-1276

Huang R-P, Darland T, Okamura D, Mercola D and Adamson ED (1994a) Suppression of v-sis-dependent transformation by the transcription factor, Egr1. Oncogene 9: 1367-1377

Huang R-P, Ngo L, Okamura D, Tucker M and Adamson ED (1994b) V-sis induces Egr-1 expression by a pathway mediated by $\mathrm{c}-\mathrm{Ha}$-Ras and c-Raf-1. J. Cell Biochem. 56: 469-479

Huang RP and Adamson ED (1995) A biological role for Egr-1 in cell survival following ultra-violet irradiation. Oncogene 10: 467-475

Huang R-P, Liu C-T, Fan Y, Mercola DA and Adamson ED (1995) Egr-1 negatively regulates human tumor cell growth via the DNA-binding domain. Cancer Res. 55 $5054-5062$

Huang R-P, Wu J-X, Fan Y and Adamson ED (1996) UV activates growth factor receptors via reactive oxygen intermediates. J. Cell Biol. 133: 211-220

Karin M (1994) Signal transduction from the cell surface to the nucleus through the phosphorylation of transcription factors. Cur. opin. in Cell Biol. 6: 415-424

Krämer B, Meichle A, Hensel G, Charnay P and Krönke M (1994) Characterization of an Krox-24/Egr-1-responsive element in the human tumor necrosis factor promoter. Biochim. Biophys. Acta 1219: 413-421

Kripke ML (1994) Ultraviolet radiation and immunology: something new under the sun. Cancer Res. 54: 6102-6105

Liu M, Dhanwada KR, Birt DF, Hecht S and Pelling JC (1994) Increase in p53 protein half-life in mouse keratinocytes following UV-B irradiation. Carcinogenesis. 15 $1089-1092$

Lowe SW, SchmittEM, Smith SW, Osborne BA and Jacks T (1993) p53 is required for radiation-induced apoptosis in mouse thymocytes. Nature 362: 847-852

Liu C, Adamson E and Mercola D (1996) Transcription factor EGR-1 suppresses the growth and transformation of human $\mathrm{HT}-1080$ fibrosacroma cells by induction of transforming growth factor $\beta 1$. Proc. Natl. Acad. Sci. USA. 93: 11831-11836

Lu $X$ and Lane DP (1993) Differential induction of transcriptionally active p53 following UV or ionizing radiation: defects in chromosome instability syndromes. Cell 75: $765-778$

Orren DK, Petersen LN and Bohr VA (1995) AUV-responsive G2 checkpoint in rodent cells. Mol. Cell Biol. 15: 3722-3730

Papathanasiou MA, Kerr NC, Robbins JH, McBride OW, Alamo IJ, Barrett SF, Hickson ID and Fornace AJJ (1991) Induction by ionizing radiation of the gadd45 gene in cultured human cells: lack of mediation by protein kinase C. Mol. Cell Biol. 11: $1009-1016$

Papavassiliou AG (1994) The CREB/ATF family of transcription factors: modulation by reversible phosphorylation. Anticancer Research. 14: 1801-1805

Petersen LN, Orren DK and Bohr VA (1995) Gene-specific and strand-specific DNA repair in the G1 and G2 phases of the cell cycle. Mol. Cell Biol. 15: 3731-3737

Radler-Pohl A, Sachsenmaier C, Gebel S, Auer H-P, Bruder JT, Rapp U, Angel P, Rahmsdorf HJ and Herrlich P (1993) UV-induced activation of AP-1 involves obligatory extranuclear steps including Raf-1 kinase. EMBO J. 12: 1005-1012 
Sachsenmaier C, Radler-Pohl A, Müller A, Herrlich P and Rahmsdorf HJ (1994a) Damage to DNA by UV light and activation of transcription factors. Biochem. Pharmacol. 47: 129-136

Sachsenmaier C, Radler-Pohl A, Zinck R, Nordheim A, Herrlich P and Rahmsdorf HJ (1994b) Involvement of growth factor receptors in the mammalian UVC response. Cell 78: $963-972$

Sluss HK, Barrett T, Derijard B and Davis RJ (1994) Signal transduction by tumor necrosis factor mediated by JNK protein kinases. Mol. Cell Biol. 14: 8376-8384
Stein B, Rahmsdorf HJ, Steffen A, Litfin M and Herrlich P (1989) UV-induced DNA damage is an intermediate step in UV-induced expression of human immunodeficiency virus type I, collagenase, c-fos, and metallothionein. Mol. Cell Biol. 9: 5169-5181

Wang XQ and Ellem KAO (1994) Heterogeneity in the HeLa cell cycle response to UVC analyzed by the BrdUrd two-parameter method. Exp. Cell Res. 212: 176189 